\title{
Comparison of Knowledge Databases to Be Used in Automated Monitoring of Orthopedic Medical Devices
}

\author{
Thibault DHALLUIN ${ }^{\mathrm{a}, \mathrm{b}, 1}$, Leslie GRAMMATICO-GUILLON ${ }^{\mathrm{a}, \mathrm{b}}$, Philippe ROSSET ${ }^{\mathrm{b}, \mathrm{c}}$ \\ and Marc CUGGIA ${ }^{\mathrm{d}}$ \\ a Department of medical information, University Hospital of Tours, Tours, France \\ ${ }^{\mathrm{b}}$ Medical school university of Tours, EA 7505 EES, Tours France \\ ${ }^{\mathrm{c}}$ Department of Orthopedic Surgery, University Hospitals of Tours, Tours, France \\ ${ }^{\mathrm{d}}$ Univ Rennes, CHU Rennes, Inserm, LTSI - UMR 1099, F-35000 Rennes, France
}

\begin{abstract}
Surveillance and traceability of medical devices (MD) is a challenge in health care systems. In the perspective of reusing EHR data to automate the monitoring of medical devices, we carried out a comparison of the main MD knowledge bases (MD-KDB) currently available in France. Four MD-KDBs (ANSM, Gudid, Exhausmed and CIOdm) were compared quantitatively and through an example of a shoulder prosthesis. The number of MDs registered differs from one MD-KDB to another. Domain terminologies used in MD-KDBs differ in terms of granularity and in the ease of querying. Waiting EUDAMED, the European MD-KDB, it seems necessary so far to use and combine information coming from several MD-KDBs to address MD monitoring.
\end{abstract}

Keywords. Public Health Surveillance, Equipment Safety, Knowledge Databases, Health Information Systems

\section{Introduction}

Designing systems for automatic surveillance and traceability of medical devices (MD) using Electronic Health Records data is a great challenge facing manufacturers, regulatory agencies and healthcare providers. To develop this kind of systems, thesauri and knowledge databases describing MD (MD-KDB) and their features allow to address interoperability issues, to perform indexing and information retrieval tasks as well as automatic reasoning. However, we are still far from having a standard, unified and worldwide MD-KDB since this domain is quite complex, vast, subject to industry competition and under different regulations between countries. In the perspective of reusing real world clinical data to automate the monitoring of orthopedic $\mathrm{MD}$, we carried out a comparison of the main MD-KDB currently available in France.

\footnotetext{
${ }^{1}$ Corresponding Author, Thibault DHALLUIN, Department of medical information, University Hospital of Tours, 2 boulevard Tonnelé - 37044 Tours CEDEX 9, France; E-mail : T.DHALLUIN@chutours.fr.
} 


\section{Material and method}

We compared four MD-KDB : ANSM [1], Gudid [2], Exhausmed [3] and CIOdm [4]. For that, we performed a quantitative comparison of the number of devices available and the number of features available in each of these databases and we compared MDKDB features on availability, consistency and the thesaurus used (Cladimed [5], LPP [6], GMDN [7], CND [8]) through an example.

\section{Results}

The four MD-KDBs are intended for supply chain and invoicing purposes rather than for health monitoring. The registration date, the reference number and the translation of device name may vary from one MD-KDB to another. Terminologies differ on the sorting of MD and the mapping differs between MD-KDB. There is a lack of technical and medical specifications on MD. Differences in content, history, and mapping with terminologies are partly due to a lack of coordination of MD-KDB updates and governance.

\section{Discussion}

In the perspective of MD monitoring, it seems so far necessary to combine several MDKDBs to verify and consolidate information. A hope is coming from EUDAMED, the European MD-KDB intended to implement the European regulation 2017/745 [9], but its development is quite challenging and requires however to take into account the difficulties of pre-existing MD-KDB to make its use possible in current practice.

\section{References}

[1] DM classes IIa, IIb, III et DMIA - Communication et liste - ANSM : Agence nationale de sécurité du médicament et des produits de santé, (n.d.). Available at: https://www.ansm.sante.fr/Activites/Mise-surle-marche-des-dispositifs-medicaux-et-dispositifs-medicaux-de-diagnostic-in-vitro-DM-DMIADMDIV/DM-classes-IIa-IIb-III-et-DMIA-Communication-et-liste/(offset)/6, Accessed January 15, 2021).

[2] AccessGUDID - Identify Your Medical Device, (n.d.). Available at: https://accessgudid.nlm.nih.gov/, Accessed January 15, 2021.

[3] Exhausmed.com: matériel médical, dispositifs médicaux, (n.d.). Available at: http://www.exhausmed.com/, Accessed January 15, 2021.

[4] PHAST - Interopérabilité sémantique, (n.d.). Available at: http://www.phast.fr/, Acc January 15, 2021.

[5] VENTURA M, CLADIMED - Association pour la classification des dispositifs médicaux, (n.d.). Available at: http://www.cladimed.com/, Accessed January 15, 2021.

[6] Liste des produits et prestations - LPP, (n.d.). Available at: https://www.ameli.fr/medecin/exerciceliberal/remuneration/nomenclatures-codage/liste-produits-prestations-lpp, Accessed January 15, 2021.

[7] GMDN Agency, (n.d.). Available at: https://www.gmdnagency.org, Accessed January 15, 2021.

[8] M. della Salute, Classificazione Nazionale dei Dispositivi medici (CND), (n.d.). Available at: http://www.salute.gov.it/portale/temi/p2_6.jsp?id=328\&area=dispositivimedici\&menu=classificazione, Accesse- January 15, 2021.

[9] Regulation (EU) 2017/745 of the European Parliament and of the Council of 5 April 2017 on medical devices, amending Directive 2001/83/EC, Regulation (EC) No 178/2002 and Regulation (EC) No 1223/2009 and repealing Council Directives 90/385/EEC and 93/42/EEC (Text with EEA relevance), 2017. Available at: http://data.europa.eu/eli/reg/2017/745/oj/eng, Accessed March 2, 2021. 